\title{
A INFORMATIZAÇÃO E A COMPETÊNCIA: UMA NOVA PROPOSTA PARA A AÇ̃̃O DOS PROFISSIONAIS DESENVOLVEDORES DE SISTEMAS TECNOLÓGICOS
}

\author{
Paulo Henrique Possas
}

Programa de Engenharia de Sistemas e Computação - Universidade Federal do Rio de Janeiro (UFRJ)

Caixa Postal 68511 - 21945-970 Rio de Janeiro - RJ - Brasil

paulo. possaseterra.com.br

Resumo. Em um ambiente atual competitivo, onde as empresas buscam mais produtividade e lucratividade com novos modelos organizacionais e tecnologia, os recursos humanos tornam se um diferencial importante conjugado a uma politica de competencias. () objetivo deste artigo é propor um novo papel aos desenvolvedores de sistemas que devem facilitar e estimular o aparecimento das competências dos usuários (individuos) dos sistemas dentro das organizações, no momento da informatização. Dessa forma, a valorização profissional para os trabalhadores e a melhoria do desempenho produtivo para as organizações tornam -se objetivos comuns.

Abstract. The organizations has been searching productivity and profitability into current competitive environment with news organizations models and technology. But the human resources conjugated with the competence politics are becoming the differential more important for the organizations The objective of this article is propose a new role of system developers which should facilitate and stimulate the emergence of users competencies into organization during technological development. This way, the professional valorization for workers and the improvement of productive performance for organizations are becoming common objectives.

\section{Introducão}

Este artigo tem o objetivo de discutir um novo papel para os desenvolvedores de sistemas no sentido de facilitar e estimular as competências dos usuários de sistemas dentro da or ganização durante o fesenvilitar e estimular as competências dos usuários de sistemas dentro da or ganização as três visões estratégicas das organizacões; a segunda fornece os conhecimentos teóricos sobre 0 novo conceito de competência discutido atualmente; a terceira reconhece os pontos de contato entre a teoria da lógica competência e o trabalho do desenvolvedor de sistemas durante o processo de desenvolvimento de sistemas. A última parte conclui sobre a importância desse papel para os desenvolvedores, usuários e para a organização. 


\section{As Organizações e as Três Visões Estratégicas: Estrutura organizacional,
Tecnologia e Pessoas}

As empresas buscam mais produtividade diante de uma concorrência atualmente acirrad causa dos resultados dos avanços tecnológicos e das pressões competitivas sociais persistenta $P_{0}$ através lo necessitam também abrir novas frentes de alcancado sustentar, cada vez mais, a reduzida lucratividade.

Estamos numa fase de criação do novo paradigma produtivo que emerge da una efeitos cruzados entre os novos modelos de gestão e de tecnolugia que emerge da união e dos paradigma tecnológico transformou a economia ecnologia [LEMOS 1999]. Esse now nova concorrência entre os agentes econômicos já existentes e uma legião global, promovendo conduziram transformações tecnológicas em processos e produtos lC transformações, novos modelos organizacionais emergiram, de qualidade. Novas formas de organizacão, tais organizadas em rede, transformações tecnológicas.$$
\text { tecnologicas. }
$$

As novas lógicas organizacionais e as novas tecnologias, no entanto, só desempenhan um novo papel, se as organizações desenvolverem os seus recursos humanosparacompenharão lidar com a complexidade tecnológica da diversidade dos produtos e com a complexidade dos desempenhos necessérios. Prestados e relevância, não só por rever competência assume as por colocar luz na relação entre a estrategia, as competências essenciais da organização [a tecnologia] e as competências
pessoais"[ZARIFIAN 2001]

A proposta descrita neste artigo é a de começar o alinhamento entre a gestão de pessoas e a estratégia tecnológica e organizacional através da disseminação da cultura proposta pela lógica competência, durante a implantação tecnológica ou informatização. Assim, a função dos desenvolvedores de sistemas não se restringiria apenas à análise de processos organizacionais è tecnologia. O novo papel dos desenvolvedores de sistemas seria o de facilitar e estimular o aparecimento das competências dos usuários (indivíduos) dos novos sistemas dentro das gan isso, os conceitos de lógica competência devem ser explicitados, para que as ações propostas aos desenvolvedores sejam bem definidas.

Cabe então definir como desenvolvedor de sistemas o responsável pelo desenvolvimento e evolução de sistemas tecnológicos para uso em processos organizacionais, com base nas definições apresentadas no currículo de referência da Sociedade Brasileira de Computação [SBC
1999].

\section{A Lógica Competência}

As competências desenvolvidas por uma organização, ou seja, as competências técnicas, de serviço, sobre processo e sociais, saem agora do círculo estreito dos pesquisadores e dos criticose entram no debate político social. A ló gica competência, conceito defendido por ZARIFIAN 2001], baseia-se em três aspectos fundamentais: a tomada de iniciativa e responsabilidade, a Inteligência prática das situações e a faculdade de mobilização de atores em torno da mesma

Em lógica competência, uma organização reativa é uma organização que sabe Em tomada de decisão, que sabe aproximar a decisão da ação, deixando assim mais descentralizar ã̃-de-obra na produção e nos serviços em que está envolvida. A competência autonomia a maiste em fazer frente a eventos de maneira pertinente e com conhecimento de profissional consiste em fazer frente a eventos de maneira pertinente e com conhecimento de
causa. E essa competência é propriedade particular do indivíduo e não do posto de trabalho. O causa. E nada mais é que uma ação competente do individuo diante de uma situação de evento. traba ñ mais o conjunto de tarefas associadas descritivamente ao cargo, mas torna-se o Ele não émento direto da competência que o indivíduo mobiliza em face de uma situação profissional cada vez mais mutável e complexa [FLEURY e FLEURY 1999].

Mas a percepção da competência não é tarefa fácil. Pode-se induzi-la através de anformações organizacionais, por exemplo. O tipo que melhor representa uma estrutura tranizacional com reconhecimento das competências é uma organização por projeto, que organifica reunir uma equipe multi-ocupacional em torno de um projeto de inovação, com objetivos precisos e por um período pré-determinado. Por isso os projetos de desenvolvimento e implantação de sistemas tecnológicos são ações estratégicas importantes para o autoconhecimento da organização, mas não podem ser observados com uma visão puramente tecnológica ou apenas como um realinhamento dos processos organizacionais. Para que essas ações estratégicas sejam exploradas em sua plenitude, o lado humano e social da mão-de-obra nelas envolvida deve ser compreendido em seus potenciais individuais de competências, que devem ser incentivadas a se desenvolverem

Segundo ZARIFIAN [ 2001], "Competência nada mais é que 'o tomar iniciativa' e 'o assumir responsabilidade' do indivíduo diante de situações profissionais com as quais se depara”. Analisando a importância dessa afirmação:

Assumir: "resulta de um procedimento pessoal do indivíduo que aceita assumir uma situação de trabalho e ser responsável por ela" [ZARIFIAN 2001, p.71]. Nem todas as pessoas estão preparadas, treinadas ou dispostas a assumir responsabilidades, e muitas não são incentivadas para tal. Delegar responsabilidades em várias empresas significa erroneamente a perda de controle por parte de supervisores e gerentes mal preparados, frustrando qualquer tipo de iniciativa por parte dos funcionários. Mesmo em tarefas mais simples e de repetição, 0 ato de assumir é importante na relação de confiança entre o chefe e o empregado, revendo assim as idéias tayloristas, muito disseminadas entre as atuais organizações. Nelas, o homem nada mais é do que uma parte da máquina e não pode (e nem deve) pensar.

Tomar iniciativa : "Devo enfrentar o problema-qualidade já identificado. Tomo a iniciativa de aplicar tal procedimento em vez do outro, em função da experiência adquirida que tenho desse tipo de situação e do conhecimento de procedimentos possiveis que posso mobilizar, ou devo enfrentar um cliente, escolhendo, a partir de uma avaliação do comportamento deste cliente, aplicar uma estratégia bem definida de desarmamento de sua insatisfação?" [ZARIFIAN 200, p.69]. O ser humano possui capacidade de imaginação e de invenção que the permite abordar o singular e o imprevisto, e isso deve ser visto como diferencial competitivo. 
Sobre situações: "O comportamento é uma situação nunca prescritivel. Não prescrever o comportamento que o indivíduo deve adotar, porque este comportamento se intrinsecamente parte da situação. A competência é o entendimento prático das situações to to apóia em conhecimentos adquiridos e os transforma na medida em que aumenta a diversider situações. Por mais situações que se imagine, o funcionário deve usar os conhecimentos avaliar e enfrentar situações inéditas"[ZARIFIAN 2001, p.69].

Possuir o entendimento prático de uma situação é saber avaliá-la, levando em comportamento de seus participantes, sejam eles materiais (máquinas) ou humanos. A avata sobre o entendimento faz parte do comportamento competente. A analogia entraça conhecimentos adquiridos e a situação de trabalho depende do grau das situações de eventos os singularidade da situação que a pessoa tem que enfrentar. Aos poucos, através das situacões enfrentadas e contornadas, as ações executadas pelo indivíduo agregam conhecimento a siè aumentando sua experiência e criando uma lógica competência que auxiliará em cada nor situação enfrentada [ZARIFIAN 2001]. A cada nova situação observada, discutida, explorada resolvida, mais o individuo agrega conhecimento a si, estando mais seguro para enfrentar nova situações que saem dos padrões cognitivos

"No entanto, para que a bagagem do conhecimento do indivíduo se transforme e aumente é preciso que a situação com que ele se defronta tenha sido plenamente explorada do ponto de vista do que há a aprender com ela" [ZARIFIAN 2001, p.71]. Quanto maior for a diversidade das situações e quanto mais as dificuldades forem sendo vencidas, mais intensamente serão modificados os conhecimentos.

E importante saber compartilhar esses conhecimentos e experiências, pois os assalariados somente se comunicarão entre si e disponibilizarão suas competências se experimentarem 0 sentimento de participar das mesmas implicações de uma situação e se forem avaliados pela chefia à base dessas implicações. Mas é possivel que, qualquer que seja o esforço para 0 compartilhamento, ele continue sendo parcial [ZARIFIAN 2001].

Outra visão possível é a baseada nas competências sociais citadas por Fleury [FLEURYe FLEURY 1999]. A comunicação é a capacidade de expressar idéias de modo claro, e a negociação significa ter a capacidade de discutir e influenciar outras pessoas positivamente, para atingir os objetivos organizacionais

Finalmente, é de grande importância o trabalho em equipe, ou seja, a criação e o trabalh com grupos de pessoas que possuem habilidades e conhecimentos diversos. Esse tipo de interação torna-se, cada vez mais, perceptível e necessário pelos empresários, mas ainda é pouco encontrado nas organizações

\section{O Desenvolvedor de Sistemas como Promotor da Lógica C ompetência}

Uma das grandes dificuldades para as organizações que se propõem a empregar uma nova tecnologa para inovão dos processos é apenas usar o momento dessa transformaç̃o para um simples automatização. A visão empresarial geralmente se restringe à idéia de que o grupo de desenvolvedores do projeto deve apenas desenhar, construir e implantar os novos sistemas, sent a discussão dos entanto, discom todo o fluxo operacional da empresa. Quando ocorre a discussão do projeto em desarm ela se restringe aos superiores hierarquicamente

pocessos, envolvendo o usuário que trabalha no processo.

Mais preocupante ainda é que os usuários podem estar envolvidovações possiveis. Não Mais ñ̃o conseguem, não podem ou não querem discuti inovaçô noções tayloristas

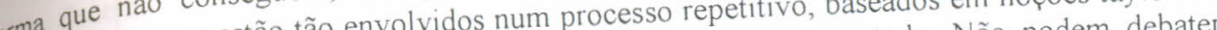
prem, porque estão tão envolem fluxo processual como um todo. Não podem debater, cons de produça lhes é permitida tal ação por parte de setr superistança implica resistencia e toda a pơque não tha Não querem a discussão, porque toda mudaça ícil de ser mantida, mas, da mão-de-obra.

${ }_{20}$ contrário, ela torna mais difícil a construção de uma logica conaria para garantir

Anda assim, mesmo envolvendo os usuários do processo, isso não búrios, para que eles Aindantação tecnológica. Deve ser proposta uma mudança aos usto que isso, para que eles uma boa impados para o novo desenho do fluxo de processo. Mars do que isso, para tecnológica estejam preparados mudança de processo e para qualquer mudança tecnologica estejam preparados para quas à sua competência devem ser francamente possivel. Para isso, as qualidades relacionadas a sua decepções comuns na construção de um estimuladas. Talvez isso explique, em grande parte, as dectąo claros e nem sempre os usuários estimuladas. Te tecnologia. Nem sempre

envolvidos estão prontos para mudanças.

No momento em que a organização "pára" para discutir os processos e implantar costringir a uma ou a duas das três tecnologias mais modernas, o olhar estategico não pode se restringir a uma

visões envolvidas numa implantação tecnologica. as arganizañes a

O ideal é possuir uma visão tecnológica, observando, desenvolvendo empresa; ter a visão tecnologias apropriadas (que nem sempre são as mals recentes) estruturando setores, para organizacional, observando a concorrência, discutindo processos e res mercado; e, finalmente, que se obte um melhor resultado de acordo com a realidade do mercado; e, fintme que se obtenha introduzir uma política de logica próprio todo o redesenhado processo até o esgotamento, dẽ que surgirão, possibilitando-lhe responsabilidades, propondo-lhe que enfrente as novas

mobilizaç̃o e a continua transformação do processo.

momento é excelente para a introdução dessa nova cultura. O papel do desenvolvedor 作 do triângulo das visões estratégicas, de sistemas move-se, saindo do lado esquerdo superior do triangulo das novo papel não deve aproximando-se do centro, conforme a flgura 2. E claro cendo ser esse o caminho mais fácil. simplesmente ser imposto aos desenvolvedores, mesmo parecendo ser essos organizacionais, mas É necessário prepará-los para não só discutir tecnologias e processos or na implantação também discutir competências sobre os recursos humanos envolvidos na implantac̃o tecnológica.

Segundo o currículo de referência da Sociedade Brasileira de Com profissionais egressos em cursos de computação devem "ter uma visão humanistica critica na consistente sobres impacto de sua atuação profissional na sociedade" e, conseqüentemente, na organização 


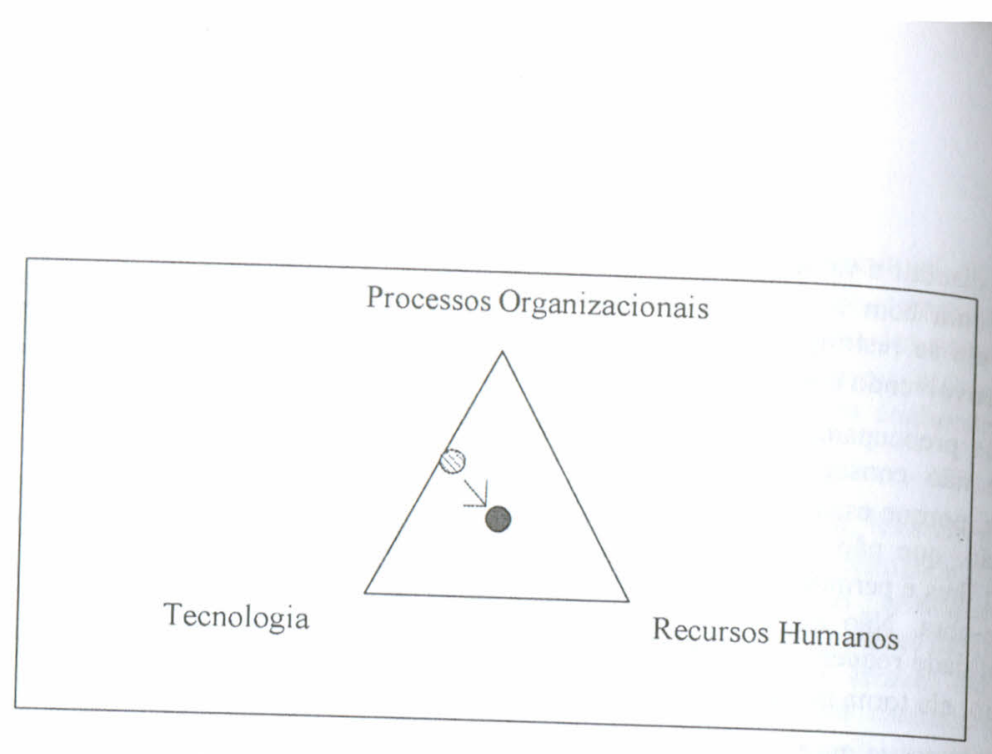

Figura 1. A nova posição do desenvolvedor de sistemas.

(fonte: autor)

O novo papel dos desenvolvedores de sistemas é facilitar e estimular o aparecimento d competências dos usuários (indivíduos) dos novos sistemas dentro das organizações Só dess forma, as pontas do triângulo aproximar-se-ão durante a fase de implantação, aliando. So dess estratégica definida previamente pela organização. Para isso, é preciscăo, aliando-se à visà poderão se tornar os facilitadores e estimulisção. Para isso, e preciso entender como eles

\subsection{O Processo Totalmente Explorado (Entendimento $\mathrm{P}$ rático)}

Para a engenharia de software, existem várias maneiras de descrever os requisitos necessários a um projeto tecnológico, o que pode ser feito através da descrição dos dados, relações e funcõos do sistema, por modelagem, através de métodra de fluxo de dados, diagrama entidade ristemas convencionais (diagrama através de sistemas orientados a objetos (dionamento, diagrama de transição de estados), ou diagramas de transicãontados a objetos (diagramas de casos de uso, diagramas de classes, diagramas de transição de estado, diagramas de comportamento). Todos esses modelos criados pelos desenvolvedores têm a mesma função dentro do projeto: a busca do entendimento completo do processo para a posterior informatização.

Nem sempre os processos são totalmente reconhecidos pelos usuários envolvidos. maioria das organizações possui enormes "distâncias burocráticas" entre seus setores e áreas, que prejudica o fluxo de processo. Conjugar a exploração de descoberta do processo feita pelo desenvolvedor com o usuário envolvido é ideal para um ambiente organizacional que preten estimular o conhecimento do indivíduo. $\mathrm{O}$ reconhecimalizal que pretende que o usuário perceba a importância de sua função na cadeia de produção como um todo faz con

\section{2 - Delegar, Assumir R esponsabilidades e a Mobilizço.}

\section{esponsabilidades e a Mobilização.}

Quando os desenvolvedores levantam informações para a construção de um sistema tecnológico, nem sempre é tarefa fácil obter dos usuários-chave as informações mais precisas sobre
Isso porque a maioria deles não se sente responsavel ou não entende a importância da processo. Isso portância do processo para a organização. Para supervisores e gerentes, delegar funcão e a impor ñó uma ação muito comum, até porque assumir responsabilidades implica esp de certo mõo acha interessante mais cobranças dos que as enfrentadas diariamente

Incentivar usuários a se sentirem responsáveis, junto com desenvolvedores do projeto, Incentiva implantação, é uma boa forma de espraiar a idéia de responsabilidade entre a pelo sucesso. Mais que isso, os desenvolvedores devem se aproximar dos usuários do novo organizaça sistema em questán no sentido de repatir com eli desenvolvimento, criando assim uma respon desenvo se estima que o desenvolvimento tecnológico auxilia os processos de uma organização quando se geralmente, não fica claro o quanto esse desenvolvimento auxiliará o usuário como No entant, gerante a organização. Os desenvolvedores já assumem a responsabilidade pela execução do projeto tecnológico para a melhoria do processo organizacional. Devem propo também a co-responsabilidade aos usuários, delegando a eles responsabilidade conjunta pelo projeto frente à estrutura organizacional. Dessa forma, a ação de "assumir responsabilidade" poderá tomar um significado mais relevante

\section{O Enfrentamento das Situações}

Freqüentemente reconhecemos usuarios que se esquivam das mudanças propostas pela informatização. Muito provavelmente se esquivam também das situações com as quais se deparam durante a execução do processo em que estão envolvidos no dia-a-dia. No decorrer do processo, muitas situações põem à prova o usuário, cabendo a ele escolher enfrentá-las ou repassá-las a outro colega ou superior hierárquico

As perguntas, durante o levantamento de requisitos de sistemas, são uma fonte geradora de muitas situações desafiadoras para os usuários envolvidos. Os desenvolvedores possuem a visão de consultores, uma visão mais abrangente e externa. Eles sugerem situações que questionam a validade das ações dos usuários dentro do processo organizacional. Se as respostas não os convencem, os desenvolvedores propõem mudanças pertinentes à melhoria do processo. Para a maioria dos usuários, mudanças são encaradas como um risco profissional. No entanto, estimular o enfrentamento é a melhor política. Por isso, o estímulo ao enfrentamento de diferentes situações deve fazer parte da cultura organizacional

\subsection{Compartilhar as Im plicações de uma Situação (a Comunicação e a N egociação)}

Neste momento, o compartilhamento de informações entre o desenvolvedor e o usuário deve se estımulado. Mas não se deve restringir o compartilhamento apenas a este momento. A ação de comunicar-se não deve ser executada apenas durante o processo de desenvolvimento dos sistemas tecnológicos e apenas entre desenvolvedores e usuários. Ela deve ser incentivada a permanecer entre os próprios usuários através de discussões que validem o processo e o sistema implantado, ou que definam as modificações cabíveis no processo e/ou na tecnologia utilizada $\quad \mathrm{O}$ ato de negociar deve ser ensinado. Os desenvolvedores negociam requisitos com os usuários. Os usuários, então, têm um papel mais extenso durante a vida organizacional. Devem negociar novas mudanças, novas tecnologias, inovações e condições de trabalho. 


\section{Considerações Finais}

Como a idéia de competência parece sair das pesquisas do meio acadêmico para se transform em uma das grandes armas de diferenciação no mundo competitivo entre as empresas, o papel desenvolvedor de sistemas começa a mudar também. A visão agora não se restringe apel organização e à tecnologia. Os desenvolvedores devem saber reconhecer usuários competes a que auxiliem no desenvolvimento tecnológico.

O desenvolvimento de soluções tecnológicas não pode se restringir aos processos organizacionais e à tecnologia empregada. Tem que se kvar em conta o recurso humano que utilizará deste avanço tecnológico. Os desenvolvedores de sistemas devem ser os geradores mudança de pensamento entre os usuários da organização. Ações como delegar e assumi responsabilidades, tomar iniciativa, enfrentar situações, mobilizar recursos humanos, est preparado para transformações, comunicar-se e negociar devem ser compartilhadas ent desenvolvedores e usuários, para que a cultura de competência permeie toda a estrutura organizacional

Porém não será fácil uma mudança de postura profissional por parte dos desenvolvedores de sistemas. Para eles, essa mudança também representa quebra da estabilidade dos padrões de esquemas cognitivos adquiridos, como para qualquer profíssional. Mesmo assim, eles estào mais preparados para mudança do que os usuários envolvidos em processos com procedimentos repetitivos, talvez por causa da faculdade de analisar, planejar e propor modificaçôes continuamente e também devido à própria renovação constante dos padrões tecnológicos.

A melhor visão é a de que a implantação de um sistema tecnológico é o momento em que a organização pára para discutir processos, tecnologia e pessoas. A função dos desenvolvedores de sistemas será a de proporcionar a introdução da lógica competência através de ações que disseminem a nova cultura organizacional, trazendo os recursos humanos de uma organização para a mesa das discussões estratégicas. Assim, as idéias de valorização profissional para os trabalhadores e a melhoria do desempenho produtivo para as organizações tornam-se objetivos comuns.

\section{Bibliografia}

CASTELLS, M., 2000, A Sociedade em Rede 4a Edição São Paulo, Ed. Paz e Terra

FLEURY, A.; FLEURY, M. T. L., 1999, Estratégias Empresariais e Formação de Competências São Paulo, Ed.Atlas

LEMOS, C., 1999, "Inovação na Era do Conhecimento" In: LASTRES, H. M. M. , ALBAGLI, S. Informação e Globalização na Era do Conecimento. Rio de Janeiro. Ed Campus, p. 122-135

SBC, 1999, Currículo de Referência. Disponivel em www sbc.org.br/educacao. Acesso em: 15 5-2003.

ZARIFIAN, P., 2001, "Competência: Definição, Implicações e Dificuldades" In: Lógica Competência São Paulo. Atlas, p.68-76 